\title{
Study of GPS Derived Total Electron Content and Scintillation Index Variations over Indian Arctic and Antarctic Stations
}

\author{
A. K. Gwal, P. Bhawre", A. A. Mansoori, and P. A. Khan \\ Space Science Laboratory, Department of Physics, Barkatullah University, Bhopal, India- 462026
}

Received 21 November 2012, accepted in final revised form 20 February 2013

\begin{abstract}
In the present study we have investigated the monthly and seasonal variability of TEC and amplitude scintillation index $\left(\mathrm{S}_{4}\right)$ over two Indian polar stations Maitri (Antarctic) and NyAlesund (Arctic), during the low solar activity period 2008. We have used the Novatel's dual frequency GPS receiver GSV4004A to accomplish this study. From our analysis we observed that TEC achieves its highest values during the months of November and December while during the month of May and June the lowest values of TEC were recorded at Maitri station. Similarly during summer season the highest values of TEC are recorded while in winter season lowest values of TEC are observed. The scintillations that occurred during the year 2008 at Maitri as well as at Ny-Alesund were generally found to be of weak type $\left(S_{4} \geq 0.1\right)$, although few cases of moderate $\left(S_{4} \geq 0.3\right)$ and strong $\left(S_{4} \geq 0.5\right)$ scintillation were also observed. The occurrence characteristics of scintillations showed that maximum scintillations at Maitri occur during the month of July and August while least scintillations occur during the month of January and February. This type of ionospheric variability can be explained on the basis of solar irradiance at Polar Regions.
\end{abstract}

Keywords: Total electron content; Scintillation index; Polar ionosphere.

() 2013 JSR Publications. ISSN: 2070-0237 (Print); 2070-0245 (Online). All rights reserved.

doi: http://dx.doi.org/10.3329/jsr.v5i2.12724 J. Sci. Res. 5 (2), 255-264 (2013)

\section{Introduction}

The variability and behavior of high latitude and polar ionosphere is very much different from that of equatorial and low latitude ionosphere. The energy transferred from solar wind to magnetosphere during solar wind magnetosphere interaction is being deposited at the Polar Regions which produces several types of disturbances in the auroral ionosphere. High latitude regions are directly affected by the entry of charged solar particles which on dissipating their energy cause auroras and thus make the ionosphere asymmetrical. One of the most interesting characteristic feature of the solar wind magnetospheric interaction occurring at Polar Regions is seen in the form of auroras.

The auroral ionosphere is subjected to adverse space weather conditions which cause significant temporal and spatial variations of electron density and density gradients resulting in highly variable (TEC) [1] and fluctuation in amplitude and phase of radio

\footnotetext{
*Corresponding author: bhawre@gmail.com
} 
signals [2]. In Polar Regions, irregularities of different scales are common, which cause fluctuations in the total electron content. The intense phase fluctuations observed along GPS satellite passes are caused by dramatic changes in TEC and demonstrate a strong horizontal gradient of TEC. Fluctuation effects and TEC gradients can have a significant impact on GPS measurements. They affect phase ambiguity resolution; increase the number of undetected and uncorrected cycle slips and loss of signal lock [3-5].

Several studies $[1,6]$ have used GPS observations from a single site or a local network to monitor TEC fluctuations and related irregularities in the high latitude ionosphere. Doherty et al. [7] and Wanninger [8] have utilized the GPS data at $30 \mathrm{~s}$ interval to study ionospheric irregularities by computing the time rate of the change of the differential carrier phase. This is equivalent to the rate of the change of the total electron content, termed ROT in units of TEC/min. Krankowski et al. [6] have demonstrated the utility of such a dataset for studying the evolution of different scale irregularities during magnetic storms at high latitudes. Pi et al. [9] have defined rate of change of TEC index (ROTI) based on standard deviation of ROT over a 5-min period.

Over past four decades, a great deal of research has revealed that ionospheric scintillation is most likely to occur in equatorial and auroral regions. At low latitudes, the scintillation is primarily controlled by increasing irregularities over the magnetic equator. After sunset, when the eastward electric field is enhanced, irregular plasma density depletions are generated on the bottom side of the nighttime equatorial $\mathrm{F}$ region and rise to higher altitudes as a result of nonlinear evolution of the generalized Rayleigh-Taylor and $\mathbf{E} \times \mathbf{B}$ instabilities [10, 11]. In the auroral zone, scintillations mainly occur in the nighttime period and exist at all local time in the polar cap region. In recent years many observations of GPS scintillations at high latitudes were reported by many researchers [12-15]. Using GPS observations from 11 high latitude stations, Aarons [16] noted that the phase fluctuation activity has a daily pattern mainly controlled by the motion of the receiver location into the auroral oval. Mitchell et al. [17] found that GPS amplitude and phase scintillations connected with steep (TEC) gradient at the southwest of Svalbard during the Halloween storm of October 2003. Later, De Franceschi et al. [18] examined the observations from a chain of GPS ionospheric scintillation and TEC receivers in Northern Europe, and investigated the dynamics of ionosphere during the storm event. A strong influence of IMF on the formation and movement of patches were reported.

Severe amplitude fading and strong phase scintillations affect the reliability of GPS navigational systems and satellite communications. Therefore, it is desirable to obtain further understanding of ionospheric scintillations and its effects on GPS by means of a receiver capable of performing in such conditions. This paper describes the monthly and seasonal variability of TEC and amplitude scintillation $\left(\mathrm{S}_{4}\right)$ index over Indian polar stations Maitri (Antarctic) and Ny-Alesund (Arctic) during the low solar activity period 2008 .

\section{Data and Method of Analysis}

Ionospheric scintillation and TEC measurements were performed using the GPS Ionospheric Scintillation and TEC monitor (GISTM) GSV 4004A. The receiver system 
was installed and operated at Indian Antarctic station, Maitri from January 2008 to January 2009 and at Arctic base station, Himadri for two months October and November 2008. The receiver computes ionospheric TEC from the GPS L1 and L2 signals. The GSV 4004A can also automatically compute and record the amplitude scintillation index $\left(\mathrm{S}_{4}\right)$ and the phase scintillation index $\left(\sigma_{\varphi)}\right.$. This receiver is capable of tracking and reporting scintillation and TEC measurements simultaneously for 10 GPS satellites in view. The GPS observables are biased by the instrumental delay therefore it is necessary to remove these biases for accurate estimation of TEC. The VTEC determination has the capability to remove the instrumental biases both from the receiver and the satellite. The instrument time delay and potential errors are corrected using the code biases.

The amplitude scintillation is monitored by computing the $\mathrm{S}_{4}$ index, which is defined as the standard deviation of the received signal power normalized to the average signal power. It is calculated for each 60 second period on a $50 \mathrm{~Hz}$ sampling rate. The $\mathrm{S}_{4}$ index is computed over 60-second intervals and stored in the Ionospheric Scintillation Monitor Receiver data log along with the phase measurements. This is referred to as the total $\mathrm{S}_{4}$ (or $\mathrm{S}_{4 \mathrm{~T}}$ ). The normalized $\mathrm{S}_{4}$ index, including the effects of ambient noise, is defined as follows:

$$
\mathrm{S}_{4 \mathrm{~T}}=\sqrt{\frac{\left\langle\mathrm{P}^{2}\right\rangle-\langle\mathrm{P}\rangle^{2}}{\langle\mathrm{P}\rangle^{2}}}
$$

The amplitude measurements are then filtered using a Low Pass Filter (LPF) and the effects of ambient noise are removed from the $S_{4}$. This is achieved by estimating the average signal-to-noise ratio over the 60-second interval. The 60-second estimates are then used to determine the expected $\mathrm{S}_{4}$ correction $\left(\mathrm{or}_{4 \mathrm{~N}_{\mathrm{o}}}\right.$ ) due to ambient noise. Phase scintillation computation is accomplished by monitoring the $\sigma_{\varphi}$ index, the standard deviation of the deterrent carrier phase computed over 1, 3, 10, 30 and $60 \mathrm{~s}$ intervals.

\section{Results and Discussion}

To study the monthly and seasonal variability of TEC at polar stations during the low solar activity period 2008 we processed the one year GPS data recorded at Antarctic station, Maitri and two month data recorded at Arctic station, Himadari.

We begin the presentation of our results with the studies carried out over Maitri followed by the studies carried out for Arctic station Ny-Alseund.

\subsection{Studies over Maitri (Antarctic)}

\subsubsection{Monthly behavior of total electron content}

The variability of TEC for all the 12 months is presented in Fig. 1. The black lines show the variation for 30 days of the month and red line shows the variation of the median 
value of the month. This figure reflects the diurnal pattern of the TEC during the different months of the year 2008. From this figure we observe that during months of September, October, November and December the TEC achieves its highest values. At the same time the diurnal variability pattern of TEC during these months is similar to that seen at equatorial or low latitudes. Similarly during the months of April, May, June and July the lowest values of TEC were recorded. The minimum values of TEC were found to occur in the month of June. We also notice that during these months the diurnal pattern does not match with pattern seen at low latitudes. Moreover, in spite of low solar activity we notice rapid fluctuations in the TEC which is a characteristic feature of polar ionosphere. This is exactly in accordance with the variability of solar radiation and solar zenith angle at high latitude regions. The polar cap receives maximum solar radiation during the month of December which is also known as polar day and complete black out is observed during the month of June when no solar radiation is present that is why this month is also known as polar night. This type of behavior of TEC in polar region depends on solar zenith angle also. Another interesting feature seen from the Fig. 1 is the normal peak shift pattern in every month. This type of peak shifting pattern depends on the solar zenith angle and the time period for which solar radiations remain present daily (length of the day).

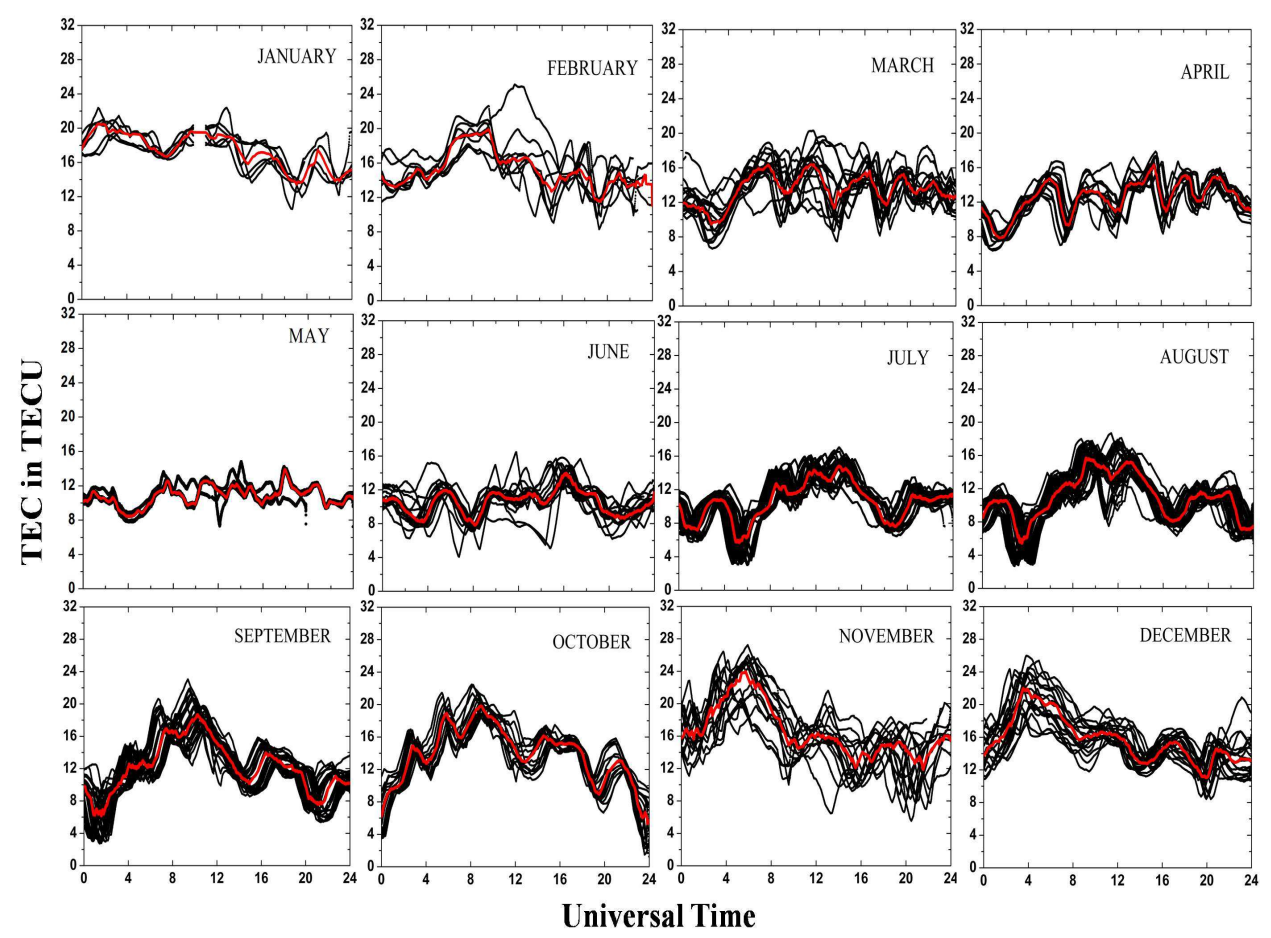

Fig. 1. Monthly variation of TEC during Jan - Dec 2008 at Maitri station. 


\subsubsection{Seasonal behavior of total electron content}

The variability of TEC during all the three seasons of the year 2008 is shown in Fig. 2. From this figure we notice that the TEC achieves its highest values during summer season while in winter season the lowest values of TEC are recorded. In summer TEC values fluctuate between 11 and 20 TECU while in winter TEC varies between 8 and 13 TECU. In equinox season the values of TEC fluctuate between 8 and 16 TECU. This type of variability can also be explained on the basis of solar irradiance. Since during summer maximum solar radiation received by the polar cap is highest so TEC achieves its highest values and accordingly for winter season.

The daily pattern of TEC for the entire year 2008 is shown in the Fig. 3. It shows an interesting feature. The peak shift pattern with amount of impinging solar radiation which the polar cap receives is clearly depicted in this figure. During summer season the solar radiation is present for full day, consequently we get a low latitude diurnal type of behavior. The TEC starts increasing in the morning and peaks in the afternoon and then starts decreasing in the evening hours. But as the autumn season arrives the length of the day goes on decreasing both on dawn and dusk side and time for which sun appears decreases progressively due to which the height of TEC peak goes on decreasing till it disappears in the winter season. In the winter a single peak is observed due to the appearance of the sun for only few noon hours after which no-sun period (Polar night) starts. After winter season as the vernal equinox is reached the sun again starts growing in a normal way and we find TEC also reverts back to its diurnal type normal pattern [13$15]$.

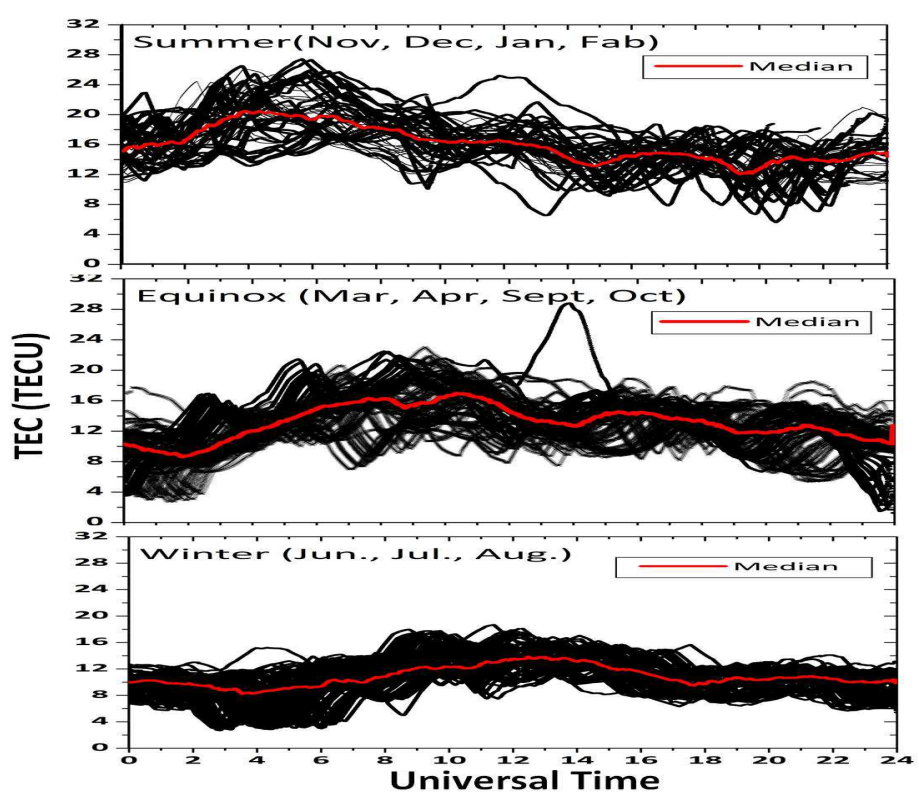

Fig. 2. Seasonal variation of TEC during January - December 2008 at Maitre station. 


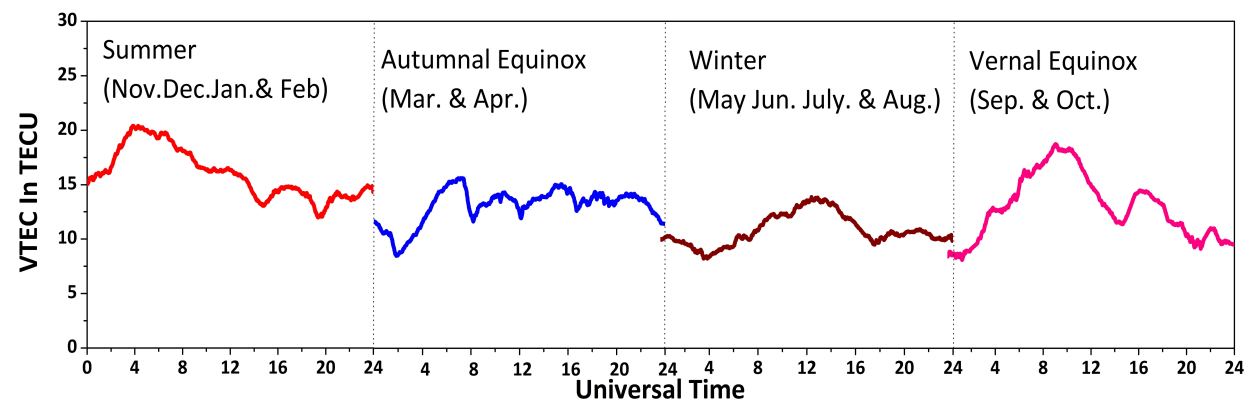

Fig. 3. Variation of monthly median TEC and shifting of TEC peak during January - December, 2008 at Maitri, Antarctica.

\subsubsection{Amplitude scintillation studies at Maitri}

The scintillation morphology is described in terms of percentage occurrence in specified threshold level of $S_{4}$ index. The study is made in terms of hourly and monthly variations of $\mathrm{S}_{4}$ index observed in GPS signals at Maitri Antarctica. Fig. 4 shows the scintillation occurrences with different thresholds of $\mathrm{S}_{4}$ index i.e. 0.1, 0.3 and 0.5. The figure shows that the scintillations observed at high latitudes are generally weak type $\left(S_{4} \geq 0.1\right)$. However few cases of moderate scintillations $\left(S_{4} \geq 0.3\right)$ and strong scintillations $\left(S_{4} \geq 0.5\right)$ were also observed. It can also be noticed that maximum scintillations occur during the months of July and August while least scintillations occur during the months of January and February. In general high latitude scintillations occur over night side auroral oval and the polar cap at all local times. High latitudes scintillations are found to be associated with large scale plasma structures known as patches, blobs and sun-aligned arcs [19, 20]. High latitude auroral irregularities are formed from a precipitation of energetic electrons along terrestrial magnetic field lines. These electrons are energized through complex interaction between the solar wind and the Earth's magnetic field, resulting in optical and UV emissions commonly known as the auroras. Evidences indicate that the dayside auroral oval plays a major role in the formation of large scale ionization structures in the polar ionosphere [19]. These structures convect across the polar cap and cause destabilization of the plasma and then develop intermediate scale irregularities by the action of the gradient drift instability mechanism [20]. The destabilization process also includes the current convective and Kelvin-Helmholtz instability [21]. It is established that precipitation of soft particles into the $\mathrm{F}$ region may play a direct role in the irregularity formation [22, 23]. In addition to patches, the sheared electric field in the cusp region is also a source of localized intermediate scale irregularities [24]. Since patches are associated with high plasma density, scintillations of satellite signals due to irregularities in the velocity shear region are expected to be weaker than patch induced scintillations [13-24] 


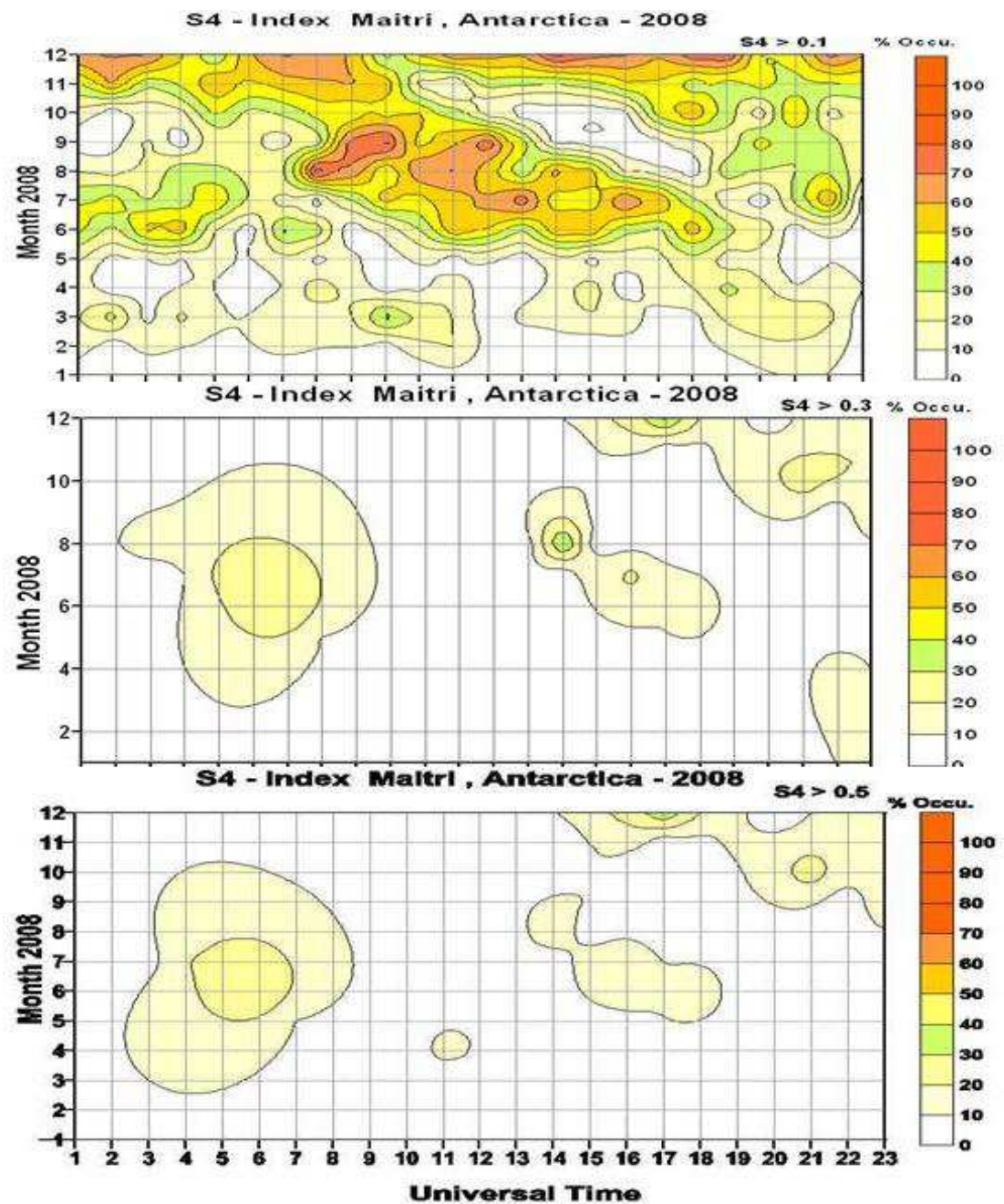

Fig. 4. Scintillation occurrences with different S4 index values at Maitri station.

\subsection{Studies over Ny-Alesund, Arctic}

We have also studied the variability of TEC over the northern hemisphere at Ny-Alesund (Indian Arctic station) during October and November months of 2008 when polar night had just started in the northern polar region. However due to non availability of data for the rest of the year the variability of TEC for the entire year could not be studied. The variability of TEC for these months is presented in the Fig. 5. During the study we found that values of TEC remain high during both the months. 
The occurrence characteristics of scintillations at Ny-Alesund during the month of October and November 2008 are shown in Fig. 6. The figure shows that scintillation activity remained higher in the month of November than in October month.

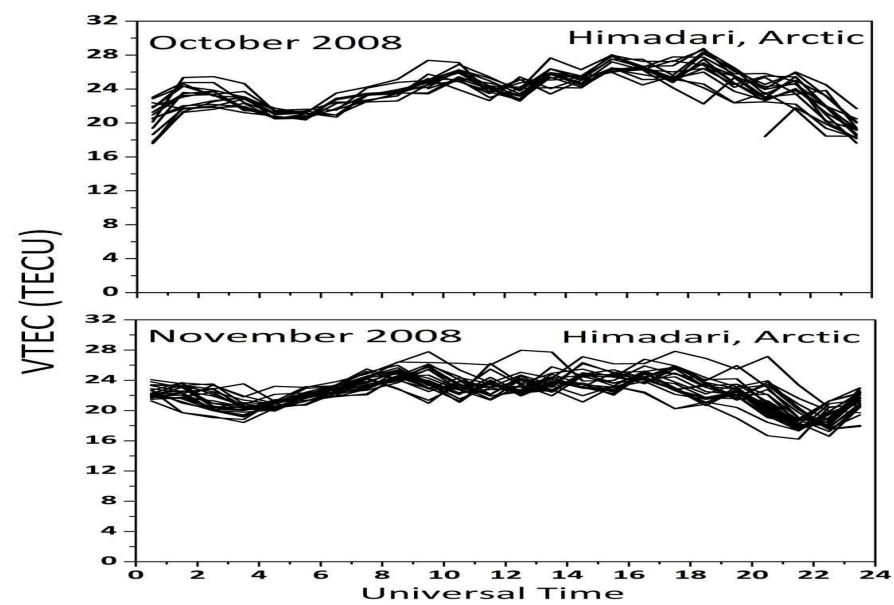

Fig. 5. Variability of TEC during October - November 2008 at Himadri station.

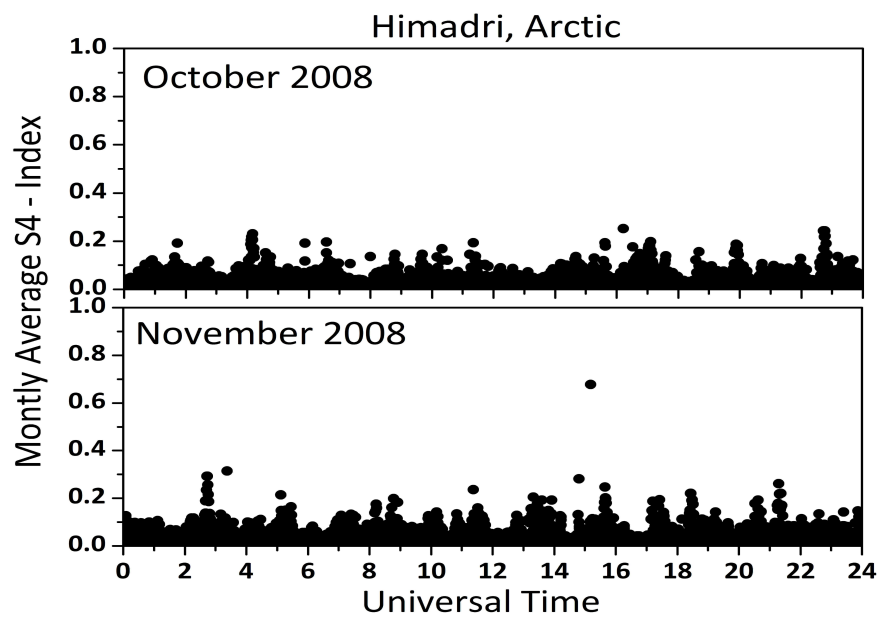

Fig. 6. Monthly average scintillation activities during October - November 2008 at Himadri station.

\section{Conclusion}

The main conclusions drawn from the present study are as follows:

a. The highest values of TEC are recorded in the months of November and December while lowest values of TEC are recorded during the months of June and July. 
Similarly, the highest values of TEC are recorded during the summer season while the lowest values are recorded in the month of winter.

b. A shift in the normal diurnal TEC peak is observed from month to month (January to December).

c. The scintillation occurrences at Maitri during low solar activity period were generally of weak type.

d. The maximum scintillation occurrences were observed during the month of July and August while least occurrences were observed in the month of January and February.

\section{Acknowledgements}

We would like to acknowledge National Center for Antarctic and Ocean Research, Goa, under the Ministry of Earth Sciences, Govt. of India for supporting this work. One of the co-authors (PB) acknowledges National Physical Laboratory, New Delhi for providing an opportunity to be at Maitri during Winter Expedition and Council of Scientific and Industrial Research (CSIR) for awarding Senior Research Fellowship, and the co-authors (PAK and AAM) acknowledge UGC, New Delhi for providing financial assistance.

\section{References}

1. J. Aarons, B. Lin, M. Mendillo, K. Liou, and M. Codrescu, J. Geophy. Res. 105, A3, .5201 (2000). http://dx.doi.org/10.1029/1999JA900409

2. S. Basu, E. Weber, T. Bullett, M. Keskinen, E. MacKenzie, P. Doherty, R. Sheehan, H. Kuenzler, P. Ning, and J. Bongiolatti, Radio Sci. 33 (6), 1885 (1998). http://dx.doi.org/10.1029/98RS01597

3. A. Krankowski, L. W. Baran, and I. I. Shagimuratov, Phys. Chem. Earth 27, 391 (2002). DOI..org/10.1016/S1474-7065(02)00017-7.

4. L. Liu, W. Wan, B. Ning, and M. L. Zhang, J. Geophy. Res. 114, A06308 (2009). http://dx.doi.org/10.1029/2009JA014244

5. L. Liu, M. He, X. Yue, B. Ning, and W. Wan, J. Geophy. Res. 115, A09307 (2010). http://dx.doi.org/10.1029/2010JA015318

6. A. Krankowski, I. I. Shagimuratov, L. W. Baran, I. I. Ephishov, Acta Geophysica Polonica 53 (2), 205 (2005). http://dx.doi.org/10.2478/v10018-007-0005-5

7. P. Doherty, E. Raffi, J. Klobuchar, and M.B. El-Arini, Proc. of ION GPS-94, Part 2, Salt Lake City, 1589 (1994). http://www.meridware.com.tw/Documents/Papers/File26.pdf

8. L. Wanninger, IGS (1995). http://www.wasoft.de/lit/igs95.pdf

9. X. Pi, A. J. Manucci, U. J. Lindqwister, and C. M. Ho, Geophy. Res. Lett. 24 (18), 2283 (1997). http://dx.doi.org/10.1029/97GL02273

10. M. C. Kelley. The earth's ionosphere, plasma physics and electrodynamics (Academic, San Diego, 1989).

11. B. G. Fejer, L. Scherlies, and E. R. De Paula, J. Geophy. Res. 104, 19859 (1999). http://dx.doi.org/10.1029/1999JA900271

12. R. W. Meggs, C. N. Mitchell, and F. Honary, GPS Solut. 12, 281 (2008). http://dx.doi.org/10.1007/s10291-008-0090-3

13. A. K. Gwal, P. Bhawre, and A. A. Mansoori, Publication in National SaGAA, Proceeding Book Chapter (2011). http://www.sagaa.co.in/pdf files/abstract.pdf 


\section{Study of GPS Derived}

14. P. Bhawre, A. A. Mansoori, P. K. Purohit, A. K. Gwal, and R. S. Dabas, Current Res. Space Sci. 2011 (ISSN. 2154-3097, ( 2011 Academic Journals Inc.). DOI:10,3923/crssaj.2011

15. P. K. Purohit, P. Bhawre, A. A. Mansoori, P. A. Khan, and A. K. Gwal, World Acad. Sci. Eng. Tech. 59, 597 (2011). www.waset.org/journals/waset/v59/v59-115.pdf

16. J. Aarons, M. Mendillo, and R. Yantosca, Radio Science 32 (4), 1535 (1997). http://dx.doi.org/10.1029/97RS00664

17. C. N. Mitchell, L. Alfonsi, G. De Franceschi, M. Lester, V. Romano, and A. W. Wernik, Geophy. Res. Lett. 32, L12S03 (2005). http://dx.doi.org/10.1029/2004GL021644

18. G. De Franceschi, L. Alfonsi, V. Romano, M. Aquino, A. Dodson, C. N. Mitchell, P. Spencer, and A. W. Wernik, J. Atmos. Solar-Terr. Phys. 70, 87 (2008).

http://dx.doi.org/10.1016/j.jastp.2007.05.018

19. E. J. Weber, J. Buchau, J. G. Moore, J. R. Sharber, R. C. Livingston, J. D. Winningham, and B. W. Reinisch, J. Geophy. Res. 89, 1683 (1984). http://dx.doi.org/10.1029/JA089iA03p01683

20. R. T. Tsunoda, Geophy. Rev. 26, 719 (1988). http://dx.doi.org/10.1029/RG026i004p00719

21. S. Basu, S. Basu, C. Senior, D. Weimer, E. Nielsen, and P. Fougere, Geophys. Res. Lett. 13 (2), 101 (1986). http://dx.doi.org/10.1029/GL013i002p00101

22. S. Basu, E. MacKenzie, S. Basu, H. Carlson, D. Hardy, F. Rich, and R. Livingston, Radio Sci. 18 (6), 1151 (1983). http://dx.doi.org/10.1029/RS018i006p01151

23. L. Kersley, S. Pryse, and N. Wheadon, Radio Sci. 23 (3), 320 (1988). http://dx.doi.org/10.1029/RS023i003p00320

24. S. Basu, S. Bssu, E. J. Weber, and W. R. Coley, Radio Sci. 23, 545 (1988). http://dx.doi.org/10.1029/RS023i004p00545 